\title{
Effects of annealing on the magnetic properties and microstructures of $\mathrm{Ta} / \mathrm{Mo} / \mathrm{CoFeB} / \mathrm{MgO} / \mathrm{Ta}$ films
}

\author{
Minghua Li ${ }^{\text {a,b*) }}$, Hui Shi a , Guoqiang Yu ${ }^{b}$, Jinhui Lu ${ }^{a}$, Xi Chen ${ }^{a}$, Gang Han ${ }^{a}$, \\ Guanghua Yu ${ }^{a}$, Pedram Khalili Amiri ${ }^{b}$ and Kang L. Wang \\ a epartment of Material Physics and Chemistry, University of Science and Technology Beijing, Beijing \\ 100083, People's Republic of China \\ ${ }^{b}$ Department of Electrical Engineering, University of California, Los Angeles, California 90095, USA
}

\begin{abstract}
We report a study on the evolution of perpendicular magnetic anisotropy (PMA) in $\mathrm{Ta} / \mathrm{Mo} / \mathrm{CoFeB} / \mathrm{MgO} / \mathrm{Ta}$ junctions annealed at $350^{\circ} \mathrm{C}$ for different periods of time. The PMA quickly developed after a short annealing time followed by a slow approach to saturation. This evolution of PMA was accompanied by structural changes. The surface roughness $\left(R_{\mathrm{q}}\right)$ gradually increased with increasing annealing time to $30 \mathrm{~min}$; further increases in annealing time resulted in a dramatic increase in $R_{\mathrm{q}}$. The effects of film composition and chemical state on magnetic anisotropy in the as-deposited $\mathrm{Ta} / \mathrm{Mo} / \mathrm{CoFeB} / \mathrm{MgO} / \mathrm{Ta}$ films and annealed films were studied. The X-ray photoelectron spectroscopy results demonstrated that more Fe oxides were formed at the $\mathrm{CoFeB} / \mathrm{MgO}$ interface after $1 \mathrm{~min}$ of annealing compared to in the as-deposited sample, which is critical to obtain the PMA. High-resolution transmission electron microscopy analysis revealed that the $\mathrm{CoFeB}$ and $\mathrm{MgO}$ layers are predominantly amorphous in sample as-deposited

*) Corresponding author. Tel: +8613521693966.

E-mail address: $\underline{\text { mhli@ustb.edu.cn }}$
\end{abstract}


and after $1 \mathrm{~min}$ annealing. However, the $\mathrm{CoFeB}$ and $\mathrm{MgO}$ layers are crystallized in sample after 30 and 60 min annealing, which is beneficial to get high PMA.

KEYWORDS: annealing, perpendicular magnetic anisotropy (PMA), X-ray photoelectron spectroscopy (XPS), High-resolution transmission electron microscopy (HRTEM), oxygen migration

\section{INTRODUCTION}

Magnetic tunnel junctions (MTJs) have been extensively studied owing to their wide range of applications in spintronic devices. Different materials have been used as ferromagnetic electrodes in MTJs; among these materials, $\mathrm{CoFeB}$ is the most commonly used in spintronic devices due to its high tunneling magnetoresistance ratio, fast speed, low damping constant, and low power consumption ${ }^{1-6}$. In all types of MTJs based on $\mathrm{MgO}$ and $\mathrm{CoFeB}$, thermal annealing after film deposition is essential to achieve a high tunnel magnetic resistance (TMR) ${ }^{7}$. Normally, $\mathrm{CoFeB} / \mathrm{MgO} / \mathrm{CoFeB}$ junctions are annealed for time periods ranging from tens of minutes to hours at temperatures between $340^{\circ} \mathrm{C}$ and $500^{\circ} \mathrm{C}^{8,9,10}$. However, both TMR and perpendicular magnetic anisotropy (PMA) are subject to deterioration after long periods of annealing due to the diffusion of Ta, B, and other elements ${ }^{11,12}$.

In MTJs, short annealing times show promise for achieving desirable characteristics. For example, high TMR was obtained by annealing at $380^{\circ} \mathrm{C}$ for shorter periods of time ${ }^{13}$. After a short period of thermal annealing, a large PMA was achieved in $\mathrm{CoFeB}$ along with a high thermal stability factor, while the Gilbert damping constant was simultaneously reduced to only $0.011^{14}$. Using extended $\mathrm{x}$-ray-absorption fine structure (EXAFS) analysis, another work reported 
the $\mathrm{B}$ depletion and crystallization of the CoFeB layers within a few seconds after the postgrowth high-temperature annealing of a $\mathrm{CoFeB} / \mathrm{MgO} / \mathrm{CoFeB}$ film ${ }^{15}$.

PMA is critical to obtain a high TMR. Therefore, it is imperative to investigate the evolution of PMA in perpendicular MTJs. PMA is thought to originate from the hybridization of $\mathrm{Fe}(\mathrm{Co})$ and $\mathrm{O}$ orbitals at the $\mathrm{CoFeB} / \mathrm{MgO}$ interface ${ }^{16}$, which is known to experience significant changes upon annealing ${ }^{17}$. Therefore, it is of great interest to investigate interfacial phenomena to determine the optimal annealing time for maximizing PMA and minimizing inter-diffusion. In our studies on $\mathrm{Ta} / \mathrm{Mo} / \mathrm{CoFeB} / \mathrm{MgO} / \mathrm{Ta}$ multilayers, we found that PMA developed after a short period of annealing and investigated the effects of the composition, interfacial chemical state, and crystallization on the magnetic properties of $\mathrm{Ta} / \mathrm{Mo} / \mathrm{CoFeB} / \mathrm{MgO} / \mathrm{Ta}$ films.

\section{EXPERIMENTAL SECTION}

$\mathrm{Ta} / \mathrm{Mo} / \mathrm{CoFeB} / \mathrm{MgO} / \mathrm{Ta}$ films were deposited on thermally oxidized $\mathrm{Si} / \mathrm{SiO}_{2}$ substrates via magnetron sputtering with a base pressure of $3.0 \times 10^{-8}$ Torr and an Ar gas (99.99\%) sputtering pressure of 3 mTorr. The substrates were rotated at $40 \mathrm{rpm}$ during deposition to insure uniform film thickness. After deposition, the samples were annealed in a vacuum furnace under a pressure of $4 \times 10^{-7}$ Torr. The magnetic properties were measured using a vibrating sample magnetometer (VSM), and the anomalous Hall effect (AHE) resistance was determined using a standard four-point technique with a test current of $1 \mathrm{~mA}$ at room temperature. The magnetic properties of the system were evaluated based on the AHE using a standard four-point technique, which has been widely used to characterize perpendicular ferromagnetic films ${ }^{18,19}$.The elemental chemical states were investigated by X-ray photoelectron spectroscopy (XPS; ESCALAB 250Xi). The chamber vacuum before XPS analysis was better than $3 \times 10^{-9}$ Torr. All binding energies were adjusted using the $\mathrm{C} 1 \mathrm{~s}$ line at $284.6 \mathrm{eV}$ as a reference to eliminate the effect of surface 
charging. The roughness was measured by white light interferometry (WLI). The vertical uncertainty depends mainly on the roughness of the measured surface.For smooth surfaces, the accuracy of the measurement is limited by the accuracy of the positioning stage. The lateral positions of the height values depend on the corresponding object point that is imaged by the pixel matrix. These lateral coordinates, together with the corresponding vertical coordinates, describe the surface topography of the object. Recent developments in both instrumentation and in measurement software for WLI have increased the vertical (i.e. height) resolution of these instruments to give a capability of better than $0.01 \mathrm{~nm}$, which makes it a practical tool for measuring surface roughness in many applications. The microstructures were characterized by high-resolution transmission electron microscopy (HRTEM; Titan Themis 200). Films with structures of $\mathrm{Ta}(5 \mathrm{~nm}) / \mathrm{Mo}(1 \mathrm{~nm}) / \mathrm{CoFeB}(0.9 \mathrm{~nm}) / \mathrm{MgO}(2 \mathrm{~nm}) / \mathrm{Ta}(2 \mathrm{~nm})$ were deposited and annealed at $350^{\circ} \mathrm{C}$ for different periods of time $(0.5,1,30,60$, and $90 \mathrm{~min})$. The nominal layer thicknesses of Mo must be less than $1 \mathrm{~nm}$ because of the inter-mixture of $\mathrm{Ta} / \mathrm{Mo}$ and $\mathrm{Mo} / \mathrm{CoFeB}$ layers.

\section{RESULTS AND DISCUSSION}

Fig.1 shows the AHE response of the as-deposited samples and the samples after annealing for 1, 30, 60, and $90 \mathrm{~min}$. The as-deposited sample (black curve) exhibited in-plane magnetic anisotropy. In contrast, the samples annealed at $350^{\circ} \mathrm{C}$ for $1,30,60$, and 90 min exhibited an outof-plane magnetic anisotropy.. The hysteresis loops of the samples measured along the in-plane and out-of-plane directions are shown in Fig. 2. Figs. 2a-f show the perpendicular and in-plane $\mathrm{M}-\mathrm{H}$ curves of the as-deposited sample and the samples annealed at $350^{\circ} \mathrm{C}$ for $0.5,1,30,60$, and 
$90 \mathrm{~min}$, respectively. The as-deposited sample exhibited in-plane magnetic anisotropy (IMA). However, after annealing at $350^{\circ} \mathrm{C}$ for $0.5 \mathrm{~min}$, the easy axis transitioned from the in-plane direction to the out-of-plane direction. After annealing at $350^{\circ} \mathrm{C}$ for $30 \mathrm{~min}$, the out-of-plane magnetic hysteresis loops exhibited high remanence and good squareness, indicating that the easily magnetized axis was perpendicular to the plane of the film. The sample remained perpendicularly magnetized after annealing for longer periods of time. Annealing at a moderate temperature can rearrange elements at interfaces, resulting in the removal of disorder generated during sputtering growth, which is advantageous to obtain PMA.

To investigate the effect of annealing time on magnetic anisotropy in the $\mathrm{Ta} / \mathrm{Mo} / \mathrm{CoFeB} / \mathrm{MgO} / \mathrm{Ta}$ films, we determined the effective magnetic anisotropy energy $\left(K_{\text {eff }}\right)$ and the coercivity $\left(H_{c}\right)$ for each sample. The effective magnetic anisotropy energy (Keff) was determined for each sample by using the following expression ${ }^{20,21,22}$ :

$$
K_{e f \bar{f}}=H_{k} \times M_{s} / 2
$$

where $M s$ is the saturation magnetization and $H k$ is the effective perpendicular magnetic anisotropy field along the hard axis.

Fig.3 summarizes the dependences of $H_{c}$ and $K_{\text {eff }}$ on annealing time for each sample. As shown in Fig. 3a, $H_{c}$ increased with annealing time and reached a maximum at 90 min of annealing. The $H_{c}$ values for the samples annealed for 1 and 90 min were 24 and $34.5 \mathrm{Oe}$, respectively. Fig. $3 \mathrm{~b}$ shows that $K_{\text {eff }}$ increased dramatically with increasing annealing time and reached a maximum at an annealing time of $30 \mathrm{~min}$; upon further increases in annealing time, decreased gradually. Although the samples annealed for 0.5 and 1 min exhibited PMA, their values were only 1.8 or $2.4 \mathrm{Merg} / \mathrm{cm}^{3}$, respectively. However, compared to the sample annealed 
at $1 \mathrm{~min}$, the value nearly doubled when annealing time was increased beyond $30 \mathrm{~min}$. To be integrated into complementary metal-oxide-semiconductor transistor (CMOS) logic circuits, MTJs must exhibit high annealing stability at temperatures ranging from $350{ }^{\circ} \mathrm{C}-400^{\circ} \mathrm{C}^{3}$. In this study, the values of $\mathrm{Ta}(5 \mathrm{~nm}) / \mathrm{Mo}(1 \mathrm{~nm}) / \mathrm{CoFeB}(0.9 \mathrm{~nm}) / \mathrm{MgO}(2 \mathrm{~nm}) / \mathrm{Ta}(2 \mathrm{~nm})$ ranged from 1.8 to $5.0 \mathrm{Merg} / \mathrm{cm}^{3}$ over the tested range of annealing times, while $H_{c}$ changed from 24.0 to 34.5 Oe. These values satisfy the needs of industry in terms of annealing temperature along with the magnetic random access memory (MRAM) requirements in terms of high intensity.

In order to clarify the effects of annealing time on PMA, we investigated the properties of the $\mathrm{MgO}$ barrier layer and the $\mathrm{CoFeB} / \mathrm{MgO}$ interface using WLI, XPS, and HRTEM. We first examined the surface morphologies of the samples annealed for different times using WLI. Fig. 4 shows the dependence of the root-mean square of surface roughness $\left(R_{\mathrm{q}}\right)$ on annealing time based on the WLI measurements. $R_{\mathrm{q}}$ increased gradually with annealing time increased to 30 min. Upon further increases in annealing time, $R_{\mathrm{q}}$ increased dramatically. As shown in Fig.4, the relationship between surface roughness and the annealing time were non-monotonic.

XPS is one of the most powerful tools for the investigation of chemical bonding and oxidation states. We carefully etched the as-deposited sample and the sample annealed for $1 \mathrm{~min}$ using a time step between 0 and $75 \mathrm{~s}$. Based on the $\mathrm{Ta}, \mathrm{Mg}, \mathrm{Co}, \mathrm{Fe}$, and Mo XPS spectra (not shown), we determined that the chemical information of the $\mathrm{CoFeB} / \mathrm{MgO}$ interface and the bottom Ta layer could be revealed after Ar ion etching for 15 and $60 \mathrm{~s}$, respectively.

Fig. 5 shows Ta $4 f$, Fe $3 p$, and Mo $3 d$ XPS spectra for samples. Figs. 5a, b, and c show the Ta $4 f$ XPS spectra as-deposited (black color) and after 1 min annealing (red color) after etching for 45, 60, and $75 \mathrm{~s}$, respectively. Metal thin films vacuum deposited on $\mathrm{SiO}_{2}$ substrates made 
from thermally oxidized Si wafers may react with $\mathrm{SiO}_{2}$. The change in Gibbs free energy of this reaction is negative (i.e., the reaction is thermodynamically favorable). In this study, the atoms that were sputtered off from the target and arrived at the substrate were provided with a kinetic energy of approximately several to tens of $\mathrm{eV}$. Therefore, the reaction is dynamically possible. When a Ta thin film was vacuum deposited on an oxidized silicon wafer, $\mathrm{Ta}_{2} \mathrm{O}_{5}$ was formed at the $\mathrm{Ta} / \mathrm{SiO}_{2}$ interface ${ }^{23}$. The reaction resulted in an intermixing layer of $\mathrm{Ta} / \mathrm{Ta}_{2} \mathrm{O}_{5}$ at the $\mathrm{Ta} / \mathrm{SiO}_{2}$ interface. The XPS spectrum of Ta exhibited a strong spin-orbit splitting with the metallic Ta and Ta-oxide peaks. Based on the XPS handbook ${ }^{24}$, peak at $21.50 \mathrm{eV}$ is a metallic Ta $4 f_{7 / 2}$ peak, peak at $23.10 \mathrm{eV}$ is its $4 f_{5 / 2}$ peak, peak at $26.20 \mathrm{eV}$ is a $4 f_{7 / 2}$ peak of $\mathrm{Ta}^{5+}$, and peak at $28.10 \mathrm{eV}$ is its $4 f_{5 / 2}$ peak. In the spectrum of the film etched for $45 \mathrm{~s}$ (Fig. 5a), only small $\mathrm{Ta}_{2} \mathrm{O}_{5}$ signals could be distinguished, and strong Ta peaks were present. Increasing the etching time greatly enhanced the $\mathrm{Ta}^{5+}$ peak and weakened the Ta peak. At an etching time of $75 \mathrm{~s}$, the intensity of the $\mathrm{Ta}^{5+}$ peak

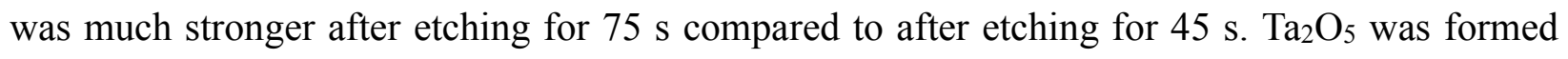
due to the oxidation of Ta adjacent to the $\mathrm{Si} / \mathrm{SiO}_{2}$ substrate on the bottom of the sample by $\mathrm{SiO}_{2}$. However, the intensity of the Ta peak after 1 min of annealing (red color) was stronger than that for the as-deposited sample (black color; Figs. $5 \mathrm{~b}$ and c). This indicates that some of the $\mathrm{Ta}_{2} \mathrm{O}_{5}$ was restored to $\mathrm{Ta}$ and $\mathrm{O}\left(\mathrm{Ta}_{2} \mathrm{O}_{5} \rightarrow 2 \mathrm{Ta}+5 \mathrm{O}\right)$ after a short period of annealing, which is in agreement with other results ${ }^{25}$. Therefore, the annealing treatment led to a decrease in the amount of $\mathrm{Ta}_{2} \mathrm{O}_{5}$ and an increase in the amount of $\mathrm{Ta}$ at the $\mathrm{Ta} / \mathrm{SiO}_{2}$ interface of the $\mathrm{Ta} / \mathrm{Mo} / \mathrm{CoFeB} / \mathrm{MgO} / \mathrm{Ta}$ film.

Figs. $5 \mathrm{~d}$ and 5 e show the computer-fitted curves of the $\mathrm{Fe} 3 p$ and $\mathrm{Mg} 2 p$ high-resolution XPS spectra of the as-deposited sample and the sample annealed for 1 min after $15 \mathrm{~s}$ of etching (which corresponds to the $\mathrm{MgO} / \mathrm{CoFeB}$ interface), respectively. According to the XPS 
handbook $^{21}$, the peaks located at $\sim 50.0 \mathrm{eV}, 52.7 \mathrm{eV}$, and $54.7 \mathrm{eV}$ correspond to the $\mathrm{Mg} 2 p$, metallic $\mathrm{Fe} 3 p$, and $\mathrm{Fe}$ oxide $3 p$ states, respectively, indicating that the interfacial $\mathrm{Fe}$ atoms were partially oxidized. However, the ratio of Fe oxide to metallic Fe calculated from the areas of the fitted curves was $0.18: 1$ for the as-deposited sample and $0.26: 1$ for the sample annealed for 1 min. This indicates that more Fe oxide was formed in the ferromagnetic layers of the annealed sample.The $\mathrm{Mg} 2 \mathrm{p}$ peak also shifted to higher binding energies after annealing. The analytical error in quantitative analysis of XPS is usually less than $10 \%$. PMA in $\mathrm{CoFeB} / \mathrm{MgO}$ structures originates from the hybridization of $\mathrm{Fe}(\mathrm{Co})$ and $\mathrm{O}$ orbitals at the interface of $\mathrm{CoFeB} / \mathrm{MgO}$; thus, the formation of moderate Fe oxide is beneficial for the generation of PMA.

Fig. $5 \mathrm{f}$ shows the Mo $3 d$ XPS spectrum of the $\mathrm{Ta} / \mathrm{Mo} / \mathrm{CoFeB} / \mathrm{MgO} / \mathrm{Ta}$ film etched for $15 \mathrm{~s}$ after 1 min annealing. The corresponding Mo $3 d$ photoelectron spectrum showed only metallic Mo components, without any detectable trace of oxide peaks, along with a strong spin-orbit splitting with the metallic Mo $3 d_{5 / 2}$ Peak 1 at $227.2 \mathrm{eV}$ and Mo $3 d_{3 / 2}$ Peak 2 at $230.5 \mathrm{eV}$.

The microstructure was characterized by HRTEM for samples as-deposited and after 1, 30, and 60 min annealing. HRTEM image of the sample annealed for 1 and 60 min annealing are shown in Fig. 6a and 6b, respectively. The bottom and top Ta is definitely amorphous for samples after $1 \mathrm{~min}$ annealing. The $\mathrm{CoFeB}$ and $\mathrm{MgO}$ layers are also predominantly amorphous, since the lattice fringes are not visible in the $\mathrm{CoFeB}$ and $\mathrm{MgO}$ layers, indicating these layers are amorphous.The interface between $\mathrm{CoFeB}$ layer and $\mathrm{MgO}$ layer is ambiguous in sample after $1 \mathrm{~min}$ annealing (Fig.6a). It is same as that of the sample as-deposited. However, the CoFeB and $\mathrm{MgO}$ layers are crystallized in sample after 60 min annealing. The fast Fourier transforms (FFTs) of the square areas "C," "D," and "E" are shown in Figs. 6c, 6d, and 6e, where in the spots can be identified as the fcc (001) plane of $\mathrm{MgO}$, bcc (001) plane of $\mathrm{CoFeB}$, and bcc (110) plane of 
Mo. These results demonstrate that the Mo inserted layer of the bcc structure had a (110) texture, whereas the $\mathrm{CoFeB}$ and $\mathrm{MgO}$ layers exhibited bcc (001) and fcc (001) textured, respectively. The $\mathrm{MgO}$ barrier interface became sharper and smoother after $60 \mathrm{~min}$ annealing. It's same as that of the sample after 30 min annealing. Fig. 6f shows the line profile of energy-dispersive X-ray spectroscopy (EDX) for the sample used for TEM observation. The peaks of the composition elements were detected from the top area in the following order; Ta, Co, Mo, Fe, B, O and $\mathrm{Mg}$, respectively. The line profile showed that B and Mo likely diffuse during thermal annealing. This result indicates an inter-diffusion event at the $\mathrm{CoFeB} / \mathrm{MgO}$ interface. However, this interdiffusion event seems to not affect the crystalline structures in our samples.

The interfacial perpendicular anisotropy between oxide and ferromagnetic metal (Fe/MgO) was previously predicted by first-principles calculation and attributed to the hybridization of the Fe $3 \mathrm{~d}$ and $\mathrm{O} 2 \mathrm{p}$ orbitals ${ }^{16}$. This means that the PMA for a ferromagnetic/oxide interface strongly depends on Fe3d-O2p orbital hybridization. In this study, the $\mathrm{Ta}_{2} \mathrm{O}_{5}$ in the $\mathrm{Ta} / \mathrm{Mo} / \mathrm{CoFeB} / \mathrm{MgO} / \mathrm{Ta}$ films was partially decomposed $\left(\mathrm{Ta}_{2} \mathrm{O}_{5} \rightarrow 2 \mathrm{Ta}+5 \mathrm{O}\right)$, and oxygen was liberated after annealing at $350^{\circ} \mathrm{C}$ for $1 \mathrm{~min}$. Thus, some of the $\mathrm{O}$ atoms released by $\mathrm{TaO}_{\mathrm{x}}$ drifted toward the Mo and CoFeB layers via diffusion paths (grain boundaries). Subsequently, some of these oxygen atoms combined with $\mathrm{Fe}$ atoms in the $\mathrm{CoFeB}$ layer, leading to the formation of more Fe oxide (the Mo XPS result shows that Mo was not oxidized). This increased the content of $\mathrm{Fe}$ oxide at the $\mathrm{CoFeB} / \mathrm{Ta}$ interface, promoting the formation of PMA. Another paper reported that interfacial oxygen migration induced the evolution of magnetic anisotropy in $\mathrm{Pt} / \mathrm{Co} / \mathrm{MgO} / \mathrm{Pt}$ films, and annealing generated an obvious improvement in the $\mathrm{Co} / \mathrm{MgO}$ interface and enhanced the effective Co-O orbital hybridization ${ }^{12}$. This suggests that in the present study, the oxygen migrated from the $\mathrm{Ta}$ layer to the $\mathrm{CoFeB} / \mathrm{MgO}$ interface, resulting in more effective $\mathrm{Fe}-\mathrm{O}$ orbital 
hybridization at the $\mathrm{CoFeB} / \mathrm{MgO}$ interface, which is critical factor for the generation of PMA in $\mathrm{Ta} / \mathrm{Mo} / \mathrm{CoFeB} / \mathrm{MgO} / \mathrm{Ta}$ films after annealing. Therefore, oxygen migration plays a decisive role in the change from IMA to PMA in $\mathrm{Ta} / \mathrm{Mo} / \mathrm{CoFeB} / \mathrm{MgO} / \mathrm{Ta}$ films after annealing.

Magnetic anisotropy in films is closely related to interfacial structure, including the interfacial chemical state and interfacial oxygen migration. Mo plays a critical role in $\mathrm{Ta}-\mathrm{O}-\mathrm{Fe}$ bonding at the $\mathrm{CoFeB} / \mathrm{Ta}$ interface; Mo causes oxygen to migrate from the Ta layer to the $\mathrm{CoFeB}$ layer in $\mathrm{Ta} / \mathrm{Mo} / \mathrm{CoFeB} / \mathrm{MgO} / \mathrm{Ta}$ films after annealing. Another study demonstrated that the insertion of an ultrathin $\mathrm{Ru}$ layer between the $\mathrm{CoFeB}$ and $\mathrm{Ta}$ layers in $\mathrm{MgO} / \mathrm{CoFeB} / \mathrm{Ta} / \mathrm{MgO}$ films effectively induces PMA without annealing ${ }^{26}$. In this study, oxygen migration at the $\mathrm{CoFeB} / \mathrm{Ta}$ interface in $\mathrm{Ta} / \mathrm{Mo} / \mathrm{CoFeB} / \mathrm{MgO} / \mathrm{Ta}$ films was induced by Mo during a short period of annealing. The Mo-induced oxygen migration altered the interfacial electronic and chemical structures at the $\mathrm{CoFeB} / \mathrm{Ta}$ interface, resulting in a $\mathrm{Ta} / \mathrm{Mo} / \mathrm{CoFeB} / \mathrm{MgO} / \mathrm{Ta}$ film with a high PMA.

\section{CONCLUSION}

We demonstrated the development of PMA in $\mathrm{CoFeB} / \mathrm{MgO}$ structures during a short period of annealing in $\mathrm{Ta} / \mathrm{Mo} / \mathrm{CoFeB} / \mathrm{MgO} / \mathrm{Ta}$ films. Mo plays a critical role in $\mathrm{Ta}-\mathrm{O}-\mathrm{Fe}$ bonding at the $\mathrm{CoFeB} / \mathrm{Ta}$ interface, causing oxygen to migrate from the Ta layer to the CoFeB layer after a short period of annealing. The XPS results show that the more formation of Fe oxide at the $\mathrm{CoFeB} / \mathrm{MgO}$ interface is critical to obtain the PMA. The HRTEM results show that the bottom and top $\mathrm{Ta}$, the $\mathrm{CoFeB}$ and $\mathrm{MgO}$ layers are predominantly amorphous in sample after $1 \mathrm{~min}$ annealing. However, the $\mathrm{CoFeB}$ and $\mathrm{MgO}$ layers exhibited bcc (001) and fcc (001) textured after 30 and 60 min annealing, which is beneficial to get high PMA. Fe oxide at the $\mathrm{CoFeB} / \mathrm{MgO}$ 
interface plays decisive roles in the evolution of magnetic anisotropy from in-plane magnetic anisotropy to perpendicular magnetic anisotropy in $\mathrm{Ta} / \mathrm{Mo} / \mathrm{CoFeB} / \mathrm{MgO} / \mathrm{Ta}$ films.

\section{ACKNOWLEDGMENTS}

The present work was supported by the National Science Foundation of China (Grant No. 51101012 and 51371025) and the Fundamental Research Funds for the Central Universities (FRF-SD-12-011A). This work was supported in part by the NSF Nanosystems Engineering Research Center for Translational Applications of Nanoscale Multiferroic Systems (TANMS). The authors would also like to acknowledge the collaboration of this research with King AbdulAziz City for Science and Technology (KACST) via The Center of Excellence for Green Nanotechnologies (CEGN).

\section{REFERENCES}

1. W. G. Wang, M. Li, S. Hageman, C.L. Chien, Electric-field assisted switching in magnetic tunnel junctions, Nat. Mater. 11(2012)64-68.

2. J.-G. Song, J. Park, J. Yoon, K. Kim, Y. Jang, K. Kim, H. Kim, Investigation of atomic layer deposition of magnesium oxide on a $\mathrm{CoFeB}$ layer for three-dimensional magnetic tunneling junctions, Journal of Alloys and Compounds 588 (2014) $716-719$.

3. T. Kawahara, K. Ito, R. Takemura, H. Ohno, Spin-transfer torque RAM technology: review and prospect, Microelectron. Reliab. 52(2012)613-627.

4. B. Cui, C. Song, G.Y. Wang, Y.Y. Wang, F. Zeng, F. Pan, Perpendicular magnetic anisotropy in $\mathrm{CoFeB} / \mathrm{X}(\mathrm{X}=\mathrm{MgO}, \mathrm{Ta}, \mathrm{W}, \mathrm{Ti}$, and Pt) multilayers, Journal of Alloys and Compounds 559 (2013) $112-115$.

5. T. Liu, Y. Zhang, J.W. Cai, H.Y. Pan, Thermally robust $\mathrm{Mo} / \mathrm{CoFeB} / \mathrm{MgO}$ trilayers with strong perpendicular magnetic anisotropy, Sci. Rep. 4(2014)5895-1-5895-6.

6. Z. M. Zeng, P. K. Amiri, I. N. Krivorotov, H. Zhao, G. Finocchio, J. P. Wang, J. A. Katine, Y. M. Huai, J. Langer, K. Galatsis, K. L. Wang, H. W. Jiang, High-Power Coherent Microwave 
Emission from Magnetic Tunnel Junction Nano-Oscillators with Perpendicular Anisotropy, ACS Nano 6(2012) 6115-6121.

7. H. Almasi, D. R. Hickey, T. Newhouse-Illige, M. Xu, M. R. Rosales, S. Nahar, J. T. Held, K. A. Mkhoyan, W. G. Wang, Enhanced tunneling magnetoresistance and perpendicular magnetic anisotropy in $\mathrm{Mo} / \mathrm{CoFeB} / \mathrm{MgO}$ magnetic tunnel junctions. Appl. Phys. Lett. 106(2015)182406-1182406-5.

8. A. Kaidatzis, C. Bran, V. Psycharis, M. Vázquez, J. M. García-Martín, D. Niarchos, Tailoring the magnetic anisotropy of $\mathrm{CoFeB} / \mathrm{MgO}$ stacks onto $\mathrm{W}$ with a Ta buffer layer, Appl. Phys. Lett. 106(2015)262401-1-262401-4.

9. S. Ikeda, J. Hayakawa, Y. Ashizawa, Y. M. Lee, K. Miura, H. Hasegawa, M. Tsunoda, F. Matsukura, H. Ohno, Tunnel magnetoresistance of $604 \%$ at $300 \mathrm{~K}$ by suppression of Ta diffusion in $\mathrm{Co} \mathrm{FeB} / \mathrm{MgO} / \mathrm{CoFeB}$ pseudo-spin-valves annealed at high temperature, Appl. Phys. Lett.93( 2008) 082508-1-082508-3.

10. G. G. An, J. B. Lee, S. M. Yang, J.H. Kim, W.S. Chung, J.P. Hong, Highly stable perpendicular magnetic anisotropies of $\mathrm{CoFeB} / \mathrm{MgO}$ frames employing $\mathrm{W}$ buffer and capping layers, Acta Materialia 87(2015)259-265.

11. N. Miyakawa, D. C. Worledge, K. Kita, Impact of Ta diffusion on the perpendicular magnetic anisotropy of Ta/CoFeB/MgO, IEEE Magn. Lett. 4(2013)1000104-1-1000104-4.

12. J. Sinha, M. Gruber, M. Kodzuka, T. Ohkubo, S. Mitani, K. Hono, M. Hayashi, Influence of boron diffusion on the perpendicular magnetic anisotropy in $\mathrm{Ta}|\mathrm{CoFeB}| \mathrm{MgO}$ ultrathin films, $\mathrm{J}$. Appl. Phys. 117(2015)043913-1-043913-6.

13. W. G. Wang, C. Ni, A. Rumaiz, Y. Wang, X. Fan, T. Moriyama, R. Cao, Q.Y. Wen, H. W. Zhang, J.Q. Xiao, Real-time evolution of tunneling magnetoresistance during annealing in $\mathrm{CoFeB} / \mathrm{MgO} / \mathrm{CoFeB}$ magnetic tunnel junctions, Appl. Phys. Lett. 92(2008)152501-1-152501-3.

14. D.S. Wang, S.Y. Lai, T.Y. Lin, C.W. Chien, D. Ellsworth, L.W. Wang, J.W. Liao, L. Lu, Y. H. Wang, M. Z. Wu, C. Lai, High thermal stability and low Gilbert damping constant of 
$\mathrm{CoFeB} / \mathrm{MgO}$ bilayer with perpendicular magnetic anisotropy by $\mathrm{Al}$ capping and rapid thermal annealing, Appl. Phys. Lett. 04(2014)142402-1-142402-5.

15. A. K. Rumaiz, J. C. Woicik, W. G. Wang, J. Jordan-Sweet, G. H. Jaffari, C. Ni, J. Q. Xiao, C. L Chien, Effects of annealing on the local structure of $\mathrm{Fe}$ and $\mathrm{Co}$ in $\mathrm{CoFeB} / \mathrm{MgO} / \mathrm{CoFeB}$ tunnel junctions: An extended x-ray-absorption fine structure study, Appl. Phys. Lett. 96(2010)112502-1-112502-3.

16. S. Ikeda, K. Miura, H. Yamamoto, K. Mizunuma, H. D. Gan, M. Endo, S. Kanai, J. Hayakawa, F. Matsukura, H. Ohno, A perpendicular-anisotropy CoFeB-MgO magnetic tunnel junction, Nat. Mater. 9(2010) 721-724.

17. J. C. Read, P. G. Mather, R. A. Buhrman, X-ray photoemission electron spectroscopy (XPS) study of $\mathrm{CoFeB} / \mathrm{MgO}$ thin film bilayers, Appl. Phys. Lett. 101 (2007)132503-1-132503-3.

18. M. Endo, S. Kanai, S. Ikeda, F. Matsukura, H. Ohno, Electric-Field Effects on Thickness Dependent Magnetic Anisotropy of Sputtered MgO/Co40Fe40B20/Ta Structures, Appl. Phys. Lett. 96(2010)212503-1-212503-31.

19. S. L. Zhang, J. Y. Zhang, A. A. Baker, S. G. Wang, G. H. Yu, T. Hesjedal, Three Dimensional Magnetic Abacus Memory. Sci. Rep. 4(2014) 6109-1-6109-5.

20 A. Kaidatzis, C. Bran, V. Psycharis, M. Vázquez, J. Mi. García-Martín,and D. Niarchos, Appl. Phys.Lett. 106, 262401 (2015).

21 S. Fukami, T. Suzuki, Y. Nakatani, N. Ishiwata, M. Yamanouchi, S. Ikeda,N. Kasai, and H. Ohno, Appl. Phys. Lett. 98, 082504 (2011).

22 R. R. Gareev, V. Zbarsky, J. Landers, I. Soldatov, R. Schäfer, M. Münzenberg, H. Wende, and P. Grünberg, Appl. Phys.Lett. 106, 132408 (2015).

23. J. R. Chen, H. R. Liauh, Y. C. Liu, F. S. Yeh, Investigations on solid state reactions between tantalum thin films and oxidized silicon crystals, J. Vacuum Sci. \& Tech. A 1(1983) 570-573. 
24. C. D. Wanger, W. M. Riggs, L. E. Davis, J. F. Moulder, G. E. Muilenberg, Handbook of Xray Photoelectron Spectroscopy, Perkin-Elmer Corp., Physical Electronics Division: Eden Prairie, MN,1979:p 190.

25. A. Cros, K. N. Tu, Stability of oxides grown on tantalum silicide surfaces, J. Appl. Phys. 60(1986)3323-3326.

26. Y. W. Liu, J. Y. Zhang, S. G. Wang, S.L. Jiang, Q.Q. Liu, X.J. Li, Z.L. Wu, Yu G.H. Ru Catalyst-Induced Perpendicular Magnetic Anisotropy in $\mathrm{MgO} / \mathrm{CoFeB} / \mathrm{Ta} / \mathrm{MgO}$ Multilayered Films, ACS Applied Materials \& Interfaces, 7(2015)26643-26648.

\section{Figure captions}

Fig.1 The AHE response of the as-deposited samples and the samples after annealing for 1, 30, 60 , and $90 \mathrm{~min}$

Fig.2 The perpendicular and in-plane $\mathrm{M}-\mathrm{H}$ curves of the as-deposited sample(a) and the samples annealed at $350^{\circ} \mathrm{C}$ for $0.5(\mathrm{~b}), 1(\mathrm{c}), 30(\mathrm{~d}), 60(\mathrm{~d})$, and $90(\mathrm{e}) \mathrm{min}$, respectively

Fig.3 The dependences of Hc and on annealing time for each sample

Fig.4 The dependence of Rq on the annealing time

Fig.5 The Ta 4f XPS spectra as-deposited (black color) and after 1 min annealing (red color) after etching for 45(a), 60(b), and 75(c) s; The computer-fitted curves of the Fe 3p and Mg $2 p$ high-resolution XPS spectra of the as-deposited(d) sample and the sample annealed for 1 min(e) after $15 \mathrm{~s}$ of etching; The Mo 3d XPS spectrum(f) etched for $15 \mathrm{~s}$ after 1 min annealing

Fig.6 HRTEM image of the sample annealed for 1min (a) and 60 min (b)annealing; The line profile of EDX for the sample after 60 min annealing(f). 


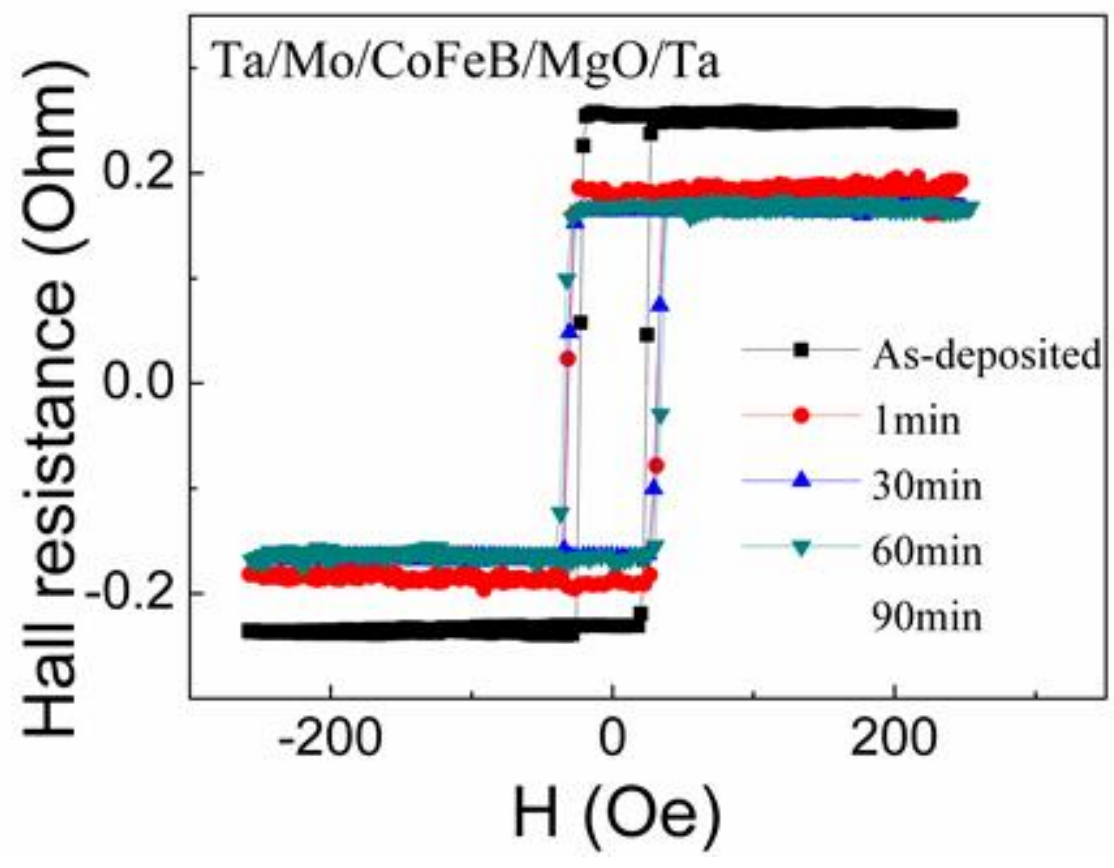



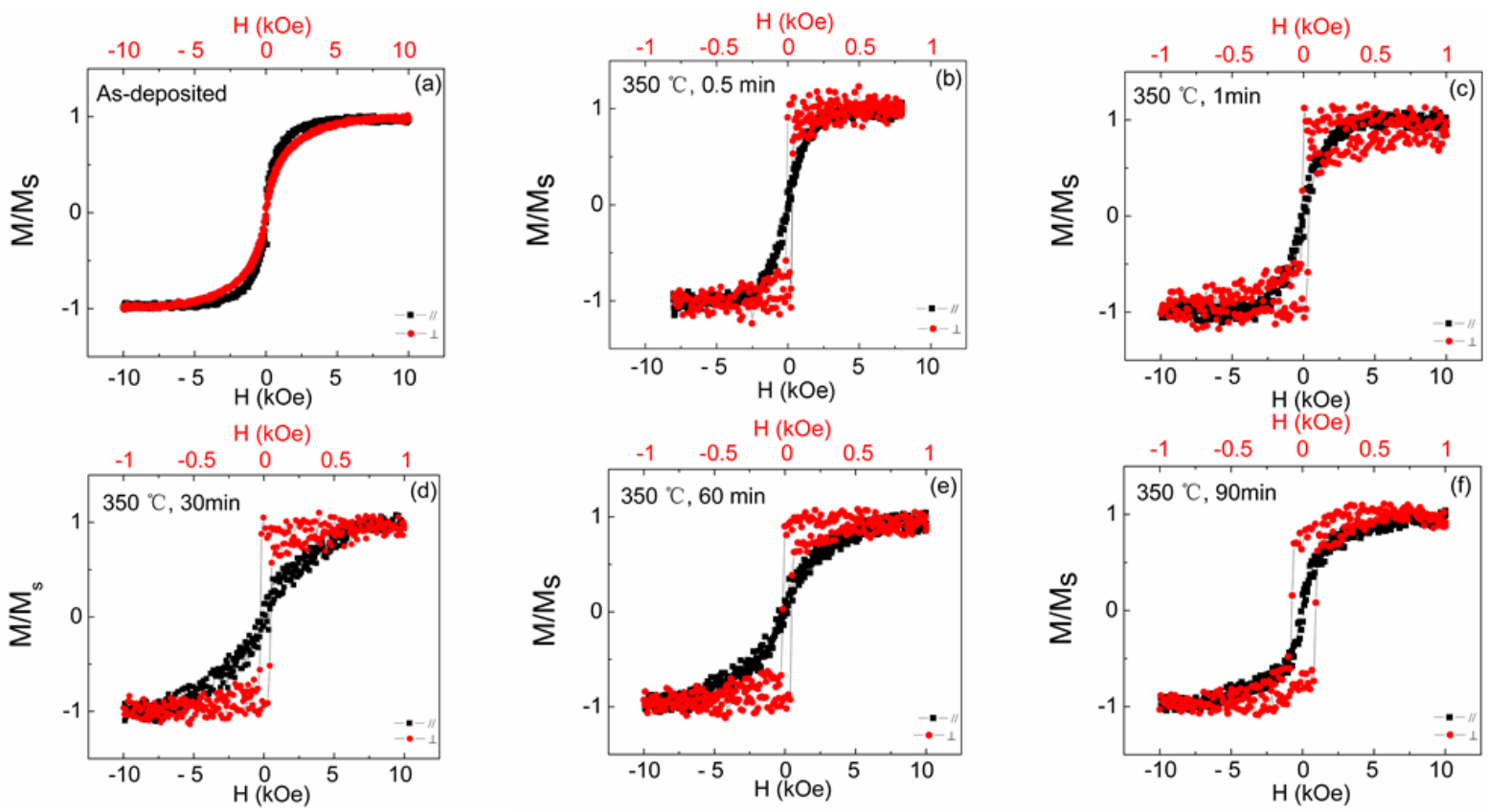

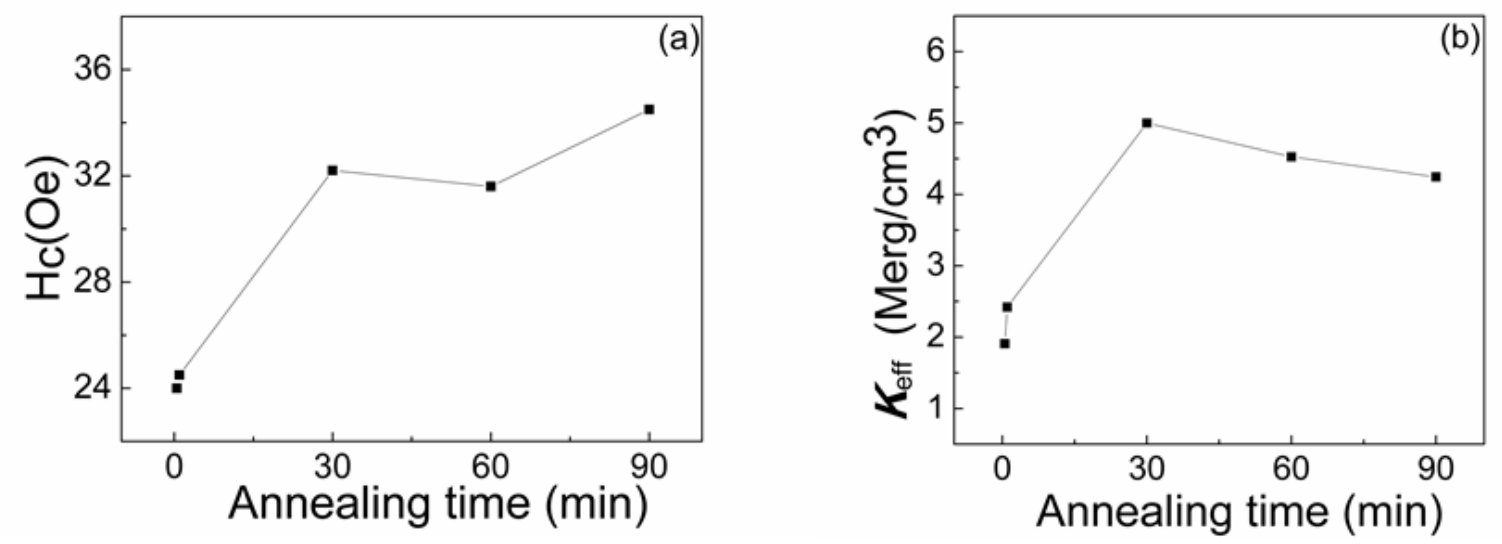


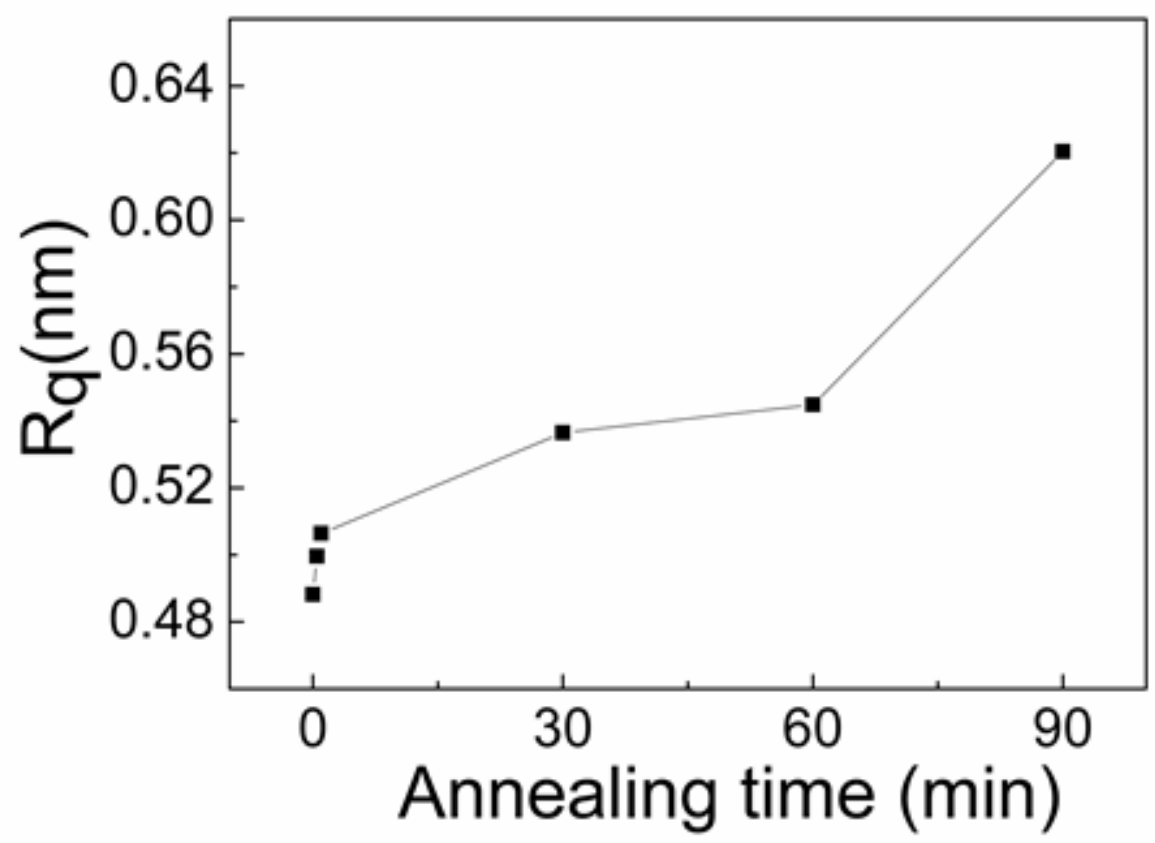



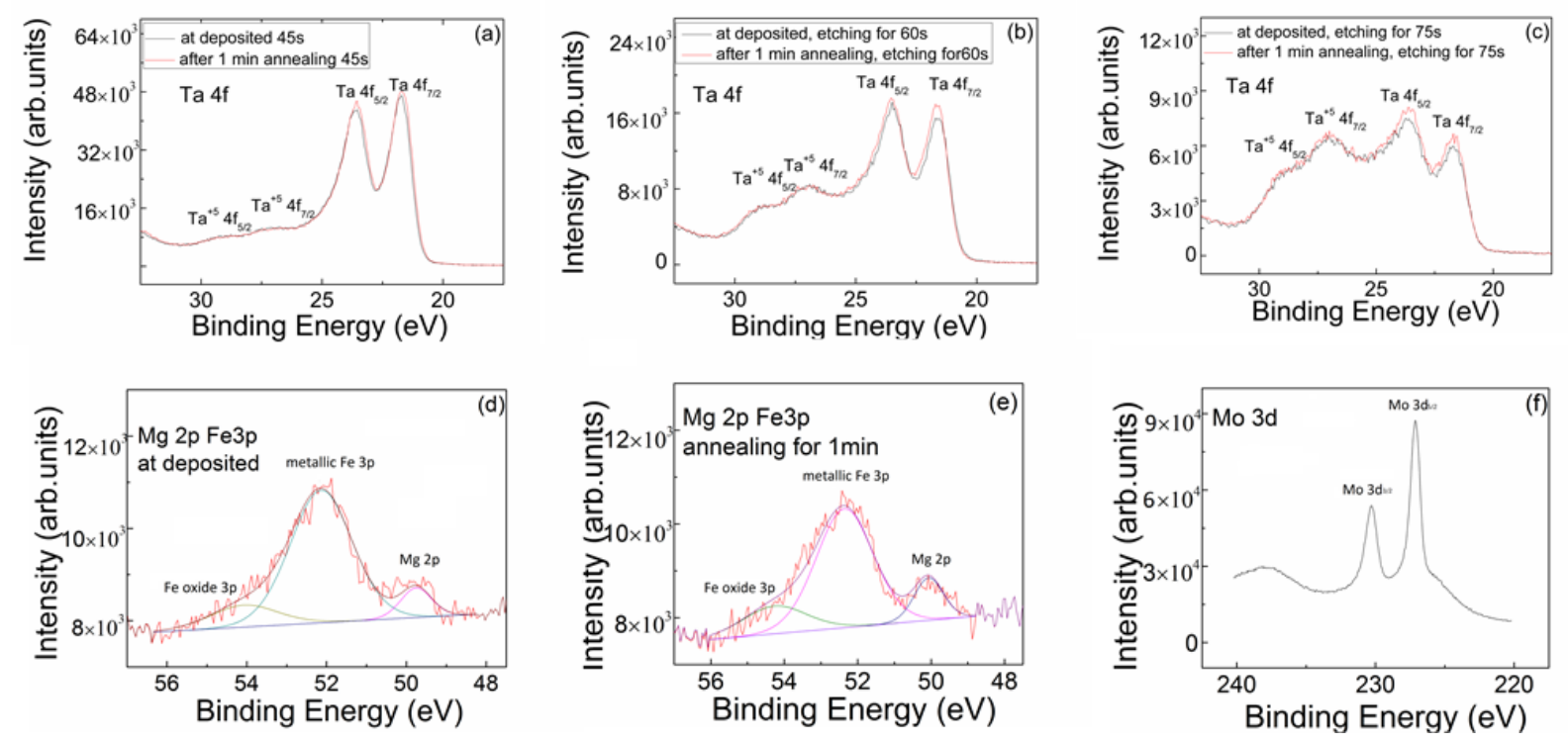

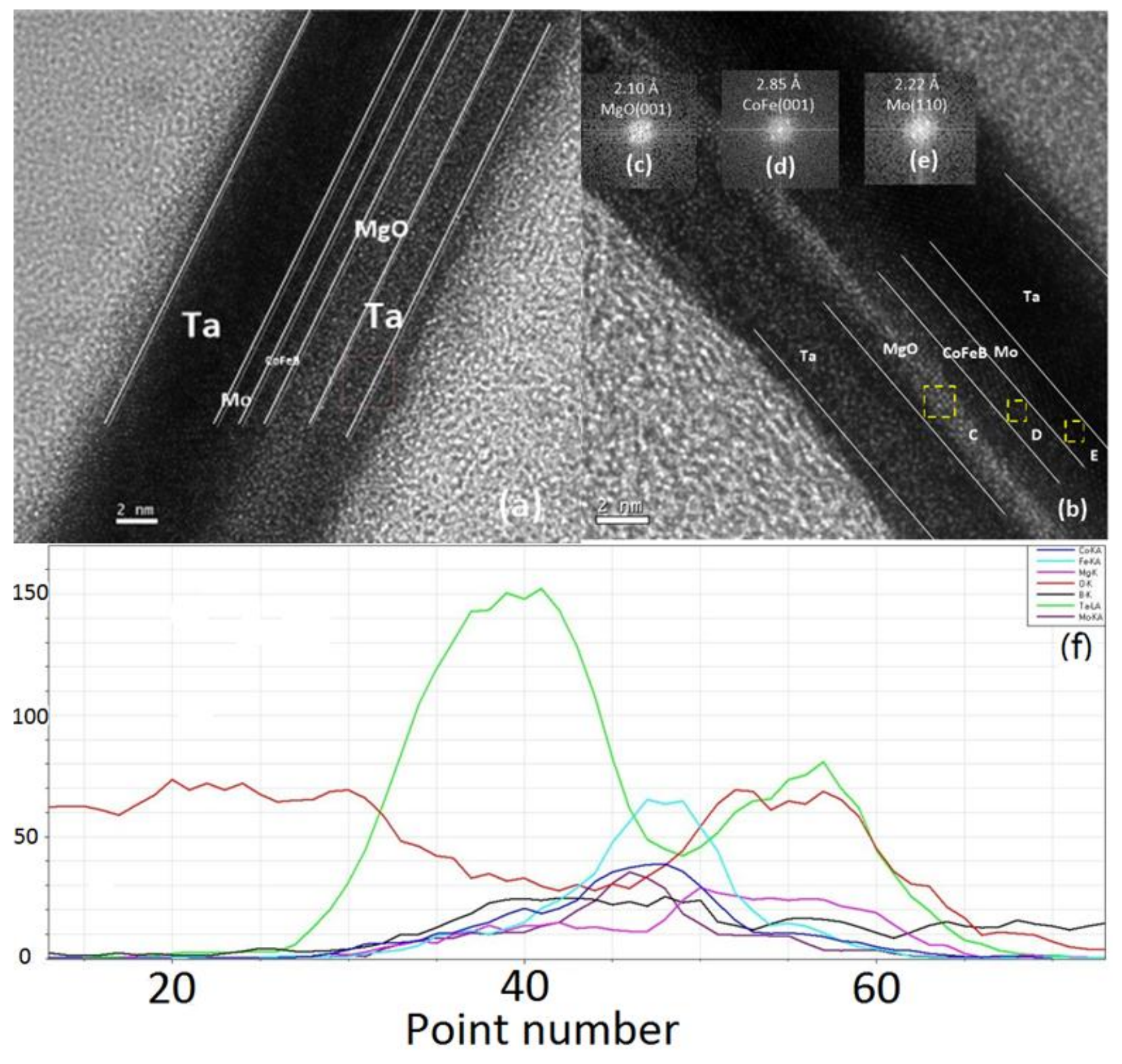